\title{
Effects of reserpine and chlorpromazine on 5-hydroxytryptamine uptake of platelets from migrainous and control subjects
}

\author{
BARBARA P. HILTON \\ From the Department of Neurochemistry, Institute of Neurology, \\ National Hospital, Queen Square, London
}

SYNOPSIS Platelet aggregation experiments confirm differences between the 5-hydroxytryptamine (5-HT) receptors of migrainous and control platelets. However, no differences have been found in 5-HT uptake, in the presence of reserpine or chlorpromazine, into migrainous and control platelets. The results support the hypothesis that receptors for 5-HT induced platelet aggregation provide a model for vascular receptors causing constriction and are distinct from those transferring 5-HT through the platelet membrane.

Differences exist between the platelet aggregation responses to 5-hydroxytryptamine (5-HT) of migrainous and control subjects (Hilton and Cumings, 1971). The aggregation responses are dependent on the availability of 5-HT uptake sites on the platelet outer membrane (Baumgartner and Born, 1968). Therefore it is possible that differences exist in the uptake of 5-HT by platelets of migrainous and control subjects and the experiments described in this paper were performed to reveal any such discrepancies.

\section{METHODS}

Samples of human blood were obtained from normal control subjects and migrainous patients (without headache and not taking any drugs) using disposable syringes and siliconized glassware throughout. Preliminary experiments to test platelet aggregation responses were carried out essentially as previously (Hilton and Cumings, 1971) except that the experiments were modified to allow platelets from one group-for example, controls-to be tested while suspended in plasma from either group (controls or migrainous subjects). Thus, platelet rich plasma from a given subject was obtained by centrifugation of heparinized blood at approximately $100 \mathrm{~g}$ for 10 minutes and $1 \mathrm{ml}$ aliquots of plasma were pipetted into conical test-tubes. After centrifugation at $200 \mathrm{~g}$ for 10 minutes clear platelet-poor plasma could be drained off the platelet button at the bottom of the test-tube. Any plasma remaining on the inside of the tube was removed by carefully wiping with tissues. One millilitre portions of platelet-poor plasma from appropriate subjects was added to the platelet buttons and the tubes were shaken on a vortex mixer to resuspend the platelets. The platelet suspensions were then tested for aggregation responses to 5-HT.

5-HT uptake experiments were carried out as described previously (Cumings and Hilton, 1971) except that ${ }^{14} \mathrm{C}$ 5-HT was employed and counted on a Packard Tri-Carb scintillation spectrophotometer in diotol scintillant (Born et al., 1972). The use of ${ }^{14} \mathrm{C}$ 5-HT enabled smaller samples of plasma to be removed from the incubation mixture for counting than had been necessary using fluorescence techniques. Thus the incubation mixture comprised $1 \mathrm{ml}$ plasma containing platelets to which was added reserpine or chlorpromazine solution (or salinethat is, $0.9 \% \mathrm{w} / \mathrm{v} \mathrm{NaCl}$ solrtion-as control) followed by ${ }^{14} \mathrm{C} 5$-HT solution. At suitable time intervals $0 \cdot 1 \mathrm{ml}$ plasma was removed using a siliconized pipette, added to $2.5 \mathrm{ml}$ saline, mixed on a vortex mixer and centrifuged ( $100 \mathrm{~g}$ for $10 \mathrm{~min}$ ) to obtain a platelet button from which the supernatant was drained carefully. The inside of the tube was wiped using tissues, to remove any remaining plasma, and the button was resuspended in $\mathbf{0 . 2} \mathrm{ml}$. saline. After freezing and thawing twice, the fractured platelets were transferred to a counting vial using glass filter 


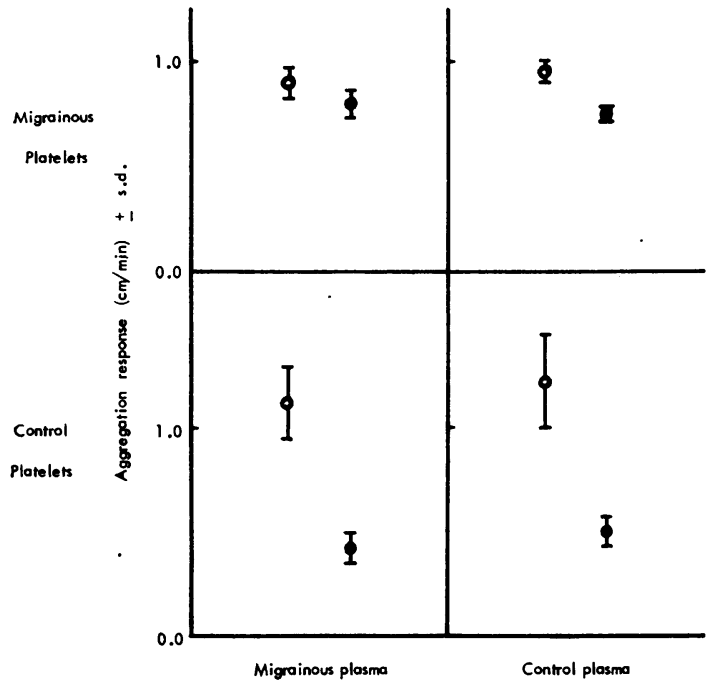

FIG. 1. Platelet aggregation results for cross-incubation experiments using migrainous and control platelets, suspended in migrainous or control plasma. Aggregation response: $\bigcirc$, to $5-\mathrm{HT}(50 \mathrm{nmol})$ directly, and 0 , to 5-HT after 1 min pre-incubation with 5-HT (50 $\mathrm{nmol})$. Each mean result was derived from four different experiments.

paper and the incubation tube was washed with diotol scintillant and the volume in the counting vial made up to $15 \mathrm{ml}$ with diotol.

The following solutions were prepared daily at the strengths shown in each aliquot $(0.1 \mathrm{ml})$ of $0.9 \%$ $\mathrm{w} / \mathrm{v} \mathrm{NaCl}$ solution, stored at $4^{\circ} \mathrm{C}$ and added to $1 \mathrm{ml}$ plasma:

5-HT (serotonin creatinine sulphate, BDH): $50 \mathrm{nmol}$

Reserpine (2.5 mg vial, Boots): 0.14 $\mu \mathrm{mol}$, $14 \mathrm{nmol}, 1 \cdot 4 \mathrm{nmol}, 0 \cdot 14 \mathrm{nmol}$

Chlorpromazine (10 mg vial, May and Baker): $1.4 \mu \mathrm{mol}, 0.14 \mu \mathrm{mol}, 14 \mathrm{nmol}, 1.4 \mathrm{nmol}$

5-hydroxytryptamine-3'-C14 creatinine sulphate (with specific activity $135 \mu \mathrm{Ci} / \mathrm{mg}$ ) was obtained from the Radiochemical Centre, Amersham. It was dissolved, together with non-radioactive 5-HT, in $0.9 \% \mathrm{w} / \mathrm{v} \mathrm{NaCl}$ solution to yield a solution containing $50 \mathrm{nmol} 5-\mathrm{HT}$, radioactivity $1.11 \mu \mathrm{Ci}$, in each $0.1 \mathrm{ml}$ aliquot used. Further dilutions were prepared containing $5.0 \mathrm{nmol} 5-\mathrm{HT}$ and $0.5 \mathrm{nmol} 5-\mathrm{HT}$, radioactivity $1 \cdot 11 \mu \mathrm{Ci}$, in each $0.1 \mathrm{ml}$.

Diotol scintillant was made as follows, with reagents obtained from British Drug Houses. 0.26 g dimethyl POPOP and $13.0 \mathrm{~g}$ PPO were dissolved in

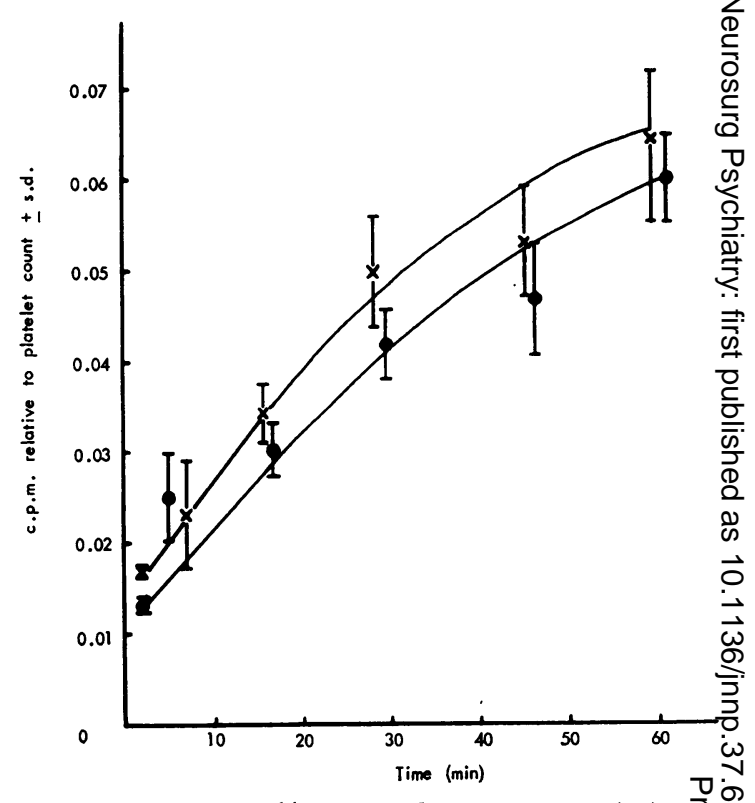

FIG. 2. Uptake of ${ }^{14} \mathrm{C}$ 5-HT by migrainous $(x)$ a) control (O) subjects. 5-HT solution (50 nmol $0 \cdot 1 \mathrm{ml}$, containing $1 \cdot 11 \mu \mathrm{Ci}{ }^{14} \mathrm{C}$ ) was added to 1 零/은 plasma. Each mean result was derived from threedifferent experiments.

$1,000 \mathrm{ml}$. AR toluene to which $208 \mathrm{~g}$ MAR naphthâtene was added and dissolved. Finally, 1,000 $\mathrm{ml}$ ARO dioxan and $600 \mathrm{ml} \mathrm{AR}$ methanol were added to the toluene and shaken gently to ensure complete mixing.o

\section{RESULTS}

Preliminary cross-incubation experiments were $\stackrel{\overline{3}}{3}$ performed in which platelets from control sub-כ jects were resuspended in plasma from migrain-o ous or control subjects. The platelets in both resuspensions gave similar aggregation responses? to 5-HT and therefore it was concluded that the aggregation response was due to the platelets and not affected by the plasma. When pre-incubatedô with 5-HT for one minute and then tested with 5 -HT both resuspensions gave reduced responses which were significantly different from responses without pre-incubation at the level $\mathbf{P}<0.05$ (see Fig. 1). The cross-incubation experiments weres repeated using migrainous platelets resuspendedn in migrainous or control plasma. The responses for both resuspensions of migrainous plateletso were similar and thus confirmed the finding thato 


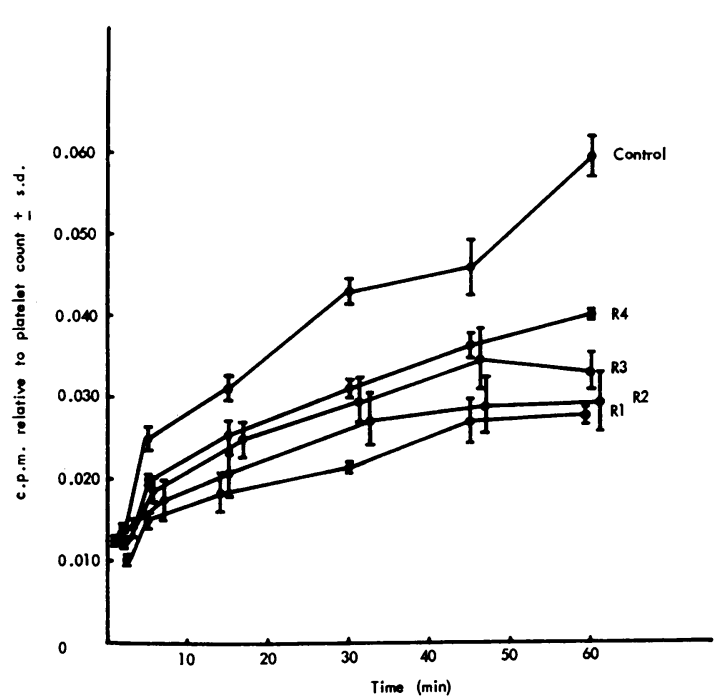

FIG. 3. Uptake of ${ }^{14} \mathrm{C}$ 5-HT by control platelets in the presence of reserpine. The 5-HT concentration was the same as in Fig. 2. The control results were obtained by adding $0.1 \mathrm{ml}$ saline in place of $0.1 \mathrm{ml}$ reserpine solution. $R 1$ comprised $0.14 \mu \mathrm{mol}$ reserpine; $R 2,14$ nmol; R3, $1.4 \mathrm{nmol}$; and R4, $0.14 \mathrm{nmol}$. Each mean result was derived from three different experiments.

aggregation response is dependent on the platelets. After pre-incubation with 5-HT the response of migrainous platelets was not significantly reduced, as can be seen in Fig. 1. This difference between control and migrainous platelets confirms earlier findings (Hilton and Cumings, 1971) and could be due to a difference in the capacity of platelets to take up 5-HT.

5-HT uptake experiments were performed using control and migrainous platelets. No significant differences were found between results for control and migrainous platelets, as can be seen in Fig. 2, which gives results for 5-HT, used at a concentration $50 \mathrm{nmol}$ per $0 \cdot 1 \mathrm{ml}$ aliquot added to $1 \mathrm{ml}$ plasma; similar curves were obtained for 5 -HT concentrations $5.0 \mathrm{nmol}$ and $0.5 \mathrm{nmol}$ per aliquot.

The gross uptake of 5-HT into the platelet is dependent on (1) uptake at the outer membrane and (2) uptake at the level of the storage organelle within the platelet. Therefore experiments were performed in the presence of chlorpromazine or reserpine which inhibit 5-HT uptake at the outer membrane and inner organelle, re-

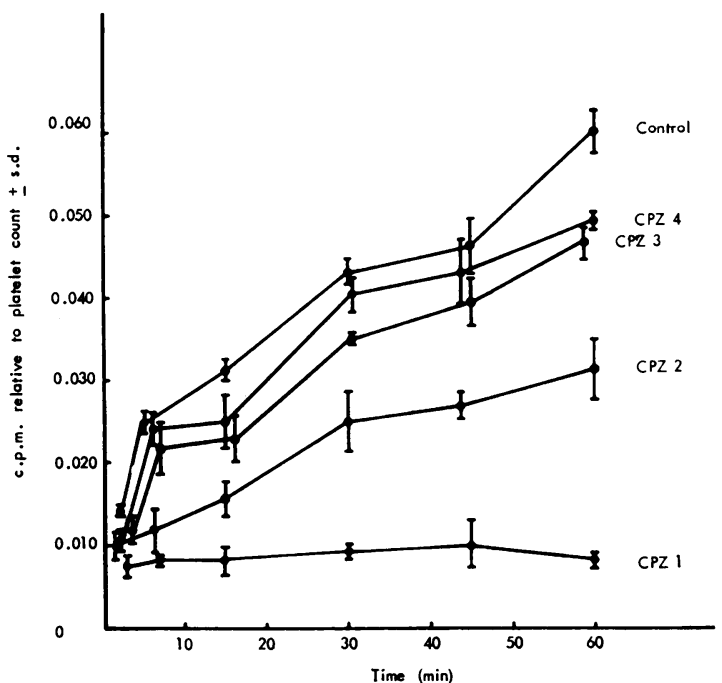

FIG. 4. Uptake of ${ }^{14} \mathrm{C} 5-H T$ by control platelets in the presence of chlorpromazine. The 5-HT concentration was the same as in Fig. 2. The control results were obtained by adding $0.1 \mathrm{ml}$ saline in place of $0.1 \mathrm{ml}$ chlorpromazine solution. CPZ1 comprised $1.4 \mu \mathrm{mol}$ chlorpromazine; CPZ2, $0 \cdot 14 \mathrm{\mu mol}$; CPZ3, $14 \mathrm{nmol}$; and CPZ4, $1.4 \mathrm{nmol}$. Each mean result was derived from three different experiments.

spectively. Figs 3 and 4 show results obtained for such incubations with control platelets; the uptake of 5 -HT alone $(50 \mathrm{nmol})$ in the absence of reserpine or chlorpromazine, has been indicated on the diagrams. Very similar results were obtained for migrainous platelets. Preliminary experiments were performed using the same concentrations of reserpine and chlorpromazine but more dilute 5 -HT aliquots $(5.0 \mathrm{nmol}, 0.5$ nmol) but no significant differences were found between uptakes by migrainous and control platelets.

\section{DISCUSSION}

The platelet aggregation results confirm that a difference exists in the platelets of migrainous subjects. Since aggregation responses are dependent on the availability of 5-HT receptor sites on the platelet outer membrane (Baumgartner and Born, 1968) these results indicate that a difference exists in the availability of such sites on migrainous membranes. The difference 
in migrainous aggregation responses reveals itself after pre-incubation with 5-HT. It would appear that during incubation the receptor sites on control platelets become occupied by $5-\mathrm{HT}$ molecules but those on migrainous platelets are less occupied by 5-HT molecules (Hilton and Cumings, 1971).

The 5-HT uptake experiments showed that uptake was rapid at first and followed the general form reported by Hardisty and Stacey (1955) and by Pletscher (1968) for active 5-HT uptake at similar concentrations. The degree of inhibition of uptake by reserpine or chlorpromazine was dose dependent and the inhibition of uptake by reserpine (concentration range $0 \cdot 14$ nmol to $14 \mathrm{nmol}$ ) overlapped that by chlorpromazine $(1.4 \mathrm{nmol}$ to $0.14 \mu \mathrm{mol})$ which is consistent with the relatively low doses of reserpine required in clinical use. The marked similarity between control and migrainous uptake results is in great contrast to the aggregation results.

It is possible that uptake experiments, since they take rather longer than aggregation experiments, are measuring a coarser variation than aggregation techniques. However, it is also possible that the two techniques measure the function of two different types of receptor, as recently postulated by Born (1973). It is thought that the receptor which responds to 5-HT aggregation tests is equivalent to the classical D-receptor of smooth muscle (Michal, 1969) and provides an experimental model for vascular 5-HT receptors causing constriction. The second type, which is occupied during 5-HT uptake experiments, is concerned with the translocation of 5-HT through the platelet membrane. Results previously obtained for ergotamine and methyl ergotamine lend weight to this theory. Both ergotamine and methyl ergotamine strongly inhibit 5-HT induced platelet aggregation but do not affect the uptake of 5-HT (Cumings and Hilton, 1971); aggregation responses of patients taking ergotamine are markedly reduced, whereas circulating levels of 5-HT are not affected (Hilton and Cumings, 1972). Thus, it is assumed that ergotamine or methyl ergotamine occupies constrictor sites (and therefore inhibits aggrega- tion) but does not occupy uptake sites (and does not affect the uptake of 5-HT nor 5-HT levels).

From these results, it would appear that in migrainous subjects the 5-HT receptors concerned with vasoconstriction are not so readily occupied as in control subjects. However, there is no difference in 5-HT uptake sites. A defect in the constrictor sites on migrainous vessels would render the vessels more vulnerable to dilatation if a fall in circulating 5-HT levels occurred, such as reported at the beginning of a migraine attack (Curran et al., 1965) and is consistent with the efficacy of vasoconstrictor drugs in migraine.

I am grateful to Dr. Marcia Wilkinson for allowing me to investigate patients in her care, at the City Migraine Clinic, and also to Professor J. N. Cumings and Professor A. N. Davison for helpful advice. This work has been supported by the Migraine Trust. The Medical Illustration Department of the Institute of Neurology prepared photographs for the figures.

\section{REFERENCES}

Baumgartner, H. R., and Born, G. V. R. (1968). Effects of 5-hydroxytryptamine on platelet aggregation. Nature, 218 , 137-141.

Born, G. V. R. (1973). The 5-hydroxytryptamine receptor of platelets and other cells. Presented at the Membrane Group Colloquium, Biochemical Society meeting, Brunel University, 1 June 1973.

Born, G. V. R., Juengjaroen, K., and Michal, F. (1972). Relative activities on and uptake by human blood platelets of 5-hydroxytryptamine and several analogues. British Journal of Pharmacology, 44, 117-139.

Cumings, J. N., and Hilton, B. P. (1971). Effects of methysergide on platelets incubated with reserpine. British Journal of Pharmacology, 42, 611-619.

Curran, D. A., Hinterberger, H., and Lance, J. W. (1965). Total plasma serotonin, 5-hydroxyindoleacetic acid and p-hydroxy-m-methoxymandelic acid excretion in normal and migrainous subjects. Brain, 88, 997-1010.

Hardisty, R. M., and Stacey, R. S. (1955). 5-hydroxytryptamine in normal human platelets. Journal of Physiology, 130, 711-720.

Hilton, B. P., and Cumings, J. N. (1971). An assessment of platelet aggregation induced by 5 -hydroxytryptamine. Journal of Clinical Pathology, 24, 250-258.

Hilton, B. P., and Cumings, J. N. (1972). 5-Hydroxytryptamine levels and platelet aggregation responses in subjects with acute migraine headache. Journal of Neurology, Neurosurgery, and Psychiatry, 35, 505-509.

Michal, F. (1969). D-receptor for serotonin on blood platelets. Nature, 221, 1253-1254.

Pletscher, A. (1968). Metabolism, transfer and storage of 5-hydroxytryptamine in blood platelets. British Journal of Pharmacology and Chemotherapy, 32, 1-16. 